\title{
Alveolar recruiting maneuver in dogs under general anesthesia: effects on alveolar ventilation, gas exchange, and respiratory mechanics
}

\author{
F. Staffieri • V. De Monte • C. De Marzo • F. Scrascia • \\ A. Crovace
}

Published online: 2 May 2010

(C) Springer Science+Business Media B.V. 2010

\begin{abstract}
The aim of this study was to evaluate the effects of a recruiting maneuver (RM) on lung aeration, gas exchange, and respiratory mechanics during general anesthesia in mechanically ventilated dogs. A thoracic computed tomography (CT) scan, an arterial blood sample, and measurement of respiratory mechanics were performed $10 \mathrm{~min}$ before (baseline) and both 5 and $30 \mathrm{~min}$ after a vital capacity RM in 10 dogs under general anesthesia. The RM was performed by inflating the lung at $40 \mathrm{~cm} \mathrm{H}_{2} \mathrm{O}$ for $20 \mathrm{~s}$. Lung aeration was estimated by analyzing the radiographic attenuation of the CT images. Lung aeration and gas exchange improved significantly 5 min after the RM compared to baseline and returned to values similar to baseline by $30 \mathrm{~min}$. Static lung compliance was not significantly affected by the RM. An RM induces a temporary improvement in lung function in healthy dogs under general anesthesia.
\end{abstract}

Keywords Dog $\cdot$ General anesthesia $\cdot$ Pulmonary atelectasis $\cdot$ Alveolar recruitment

$\begin{array}{ll}\text { Abbreviations } \\ \text { RM } & \text { recruiting maneuver } \\ \text { CRI } & \text { constant rate infusion } \\ \text { MAP } & \text { mean arterial pressure } \\ \text { DAP } & \text { diastolic arterial pressure } \\ \text { SAP } & \text { systolic arterial pressure } \\ \text { HR } & \text { heart frequency } \\ \text { PEEP } & \text { positive end-expiratory pressure } \\ \text { Ppl } & \text { Pleural pressure }\end{array}$

F. Staffieri $(\bowtie) \cdot$ V. De Monte $\cdot$ C. De Marzo $\cdot$ F. Scrascia $\cdot$ A. Crovace

Dipartimento delle Emergenze e dei Trapianti d'Organo, Sezione di Chirurgia Veterinaria,

Università degli Studi di Bari, 70010 Valenzano, Bari, Italy

e-mail: f.staffieri@veterinaria.uniba.it 


\section{Introduction}

Compression of the lung tissue (compression atelectasis) and absorption of alveolar gas (absorption atelectasis) are the main pathogenetic mechanisms involved in atelectasis formation during general anesthesia. The $\mathrm{FiO}_{2}$ that is administered to the patient during anesthesia significantly influences the formation of pulmonary atelectasis, promoting the absorption of the gas from the alveolar space into the blood since $\mathrm{O}_{2}$ is a highly diffusible gas (Staffieri et al. 2007, 2009). The aim of this study was to evaluate the effects of an alveolar recruiting maneuver (RM) on alveolar ventilation, gas exchange, and respiratory mechanics in healthy dogs under general anesthesia.

\section{Materials and methods}

The study was conducted in compliance with the Italian Welfare Act and statutes of the University of Bari relating to the use of client-owned animals under clinical investigation. Ten healthy, client-owned, mixed-breed, adult female dogs scheduled for elective ovariohysterectomy were enrolled in the study after written owner consent had been obtained. Dogs had a mean age of $32.40 \pm 11.38$ months and a body weight of $21.70 \pm$ $6.54 \mathrm{~kg}$. All dogs were premedicated with acepromazine $(30 \mu \mathrm{g} / \mathrm{kg} \mathrm{IM})$ and morphine $(0.3 \mathrm{mg} / \mathrm{kg} \mathrm{IM})$. General anesthesia was induced with propofol (4-6 mg/kg IV), and after intubation, all patients were connected to a mechanical ventilator (Siemens Servo 300). General anesthesia was maintained with a constant rate infusion (CRI) of propofol (0.4$0.5 \mathrm{mg} / \mathrm{kg} / \mathrm{min}$ ) and $0.1 \mathrm{mg} / \mathrm{kg}$ boluses of vecuronium. During premedication, induction, intubation, and connection to the breathing system, patients were manually restrained in sternal recumbence. When an adequate depth of anesthesia was achieved, dogs were positioned in dorsal recumbence. Heart rate (HR, beats/minute), systolic (SAP, mm $\mathrm{Hg}$ ), mean (MAP, mm $\mathrm{Hg}$ ), diastolic (DAP, $\mathrm{mm} \mathrm{Hg}$ ), invasive arterial pressure, respiratory rate (RR, breaths/minute), percentage of hemoglobin saturation $\left(\mathrm{SpO}_{2}, \%\right)$, and end tidal partial pressure of carbon dioxide $\left(\mathrm{EtCO}_{2}, \mathrm{~mm} \mathrm{Hg}\right)$ were continuously monitored and recorded every $5 \mathrm{~min}$. All dogs were mechanically ventilated in a volume-controlled mode, with a tidal volume $\left(\mathrm{V}_{\mathrm{T}}\right)$ of $12 \mathrm{~mL} / \mathrm{kg}$, a positive end-expiratory pressure (PEEP) of $0 \mathrm{~cm} \mathrm{H}_{2} \mathrm{O}$, an $\mathrm{I}: \mathrm{E}$ of $1: 2$, and an $\mathrm{FiO}_{2}$ of 1 . Forty minutes after positioning in dorsal recumbence, the RM was performed, inflating the lungs at an airway pressure of $40 \mathrm{~cm} \mathrm{H}_{2} \mathrm{O}$ for $20 \mathrm{~s}$. After the RM, all dogs were ventilated with the ventilator settings applied previously. Ten minutes before (Baseline) and $5\left(5^{\prime}\right)$ and $30\left(30^{\prime}\right)$ minutes after the RM lung aeration, gas exchange and respiratory mechanics were evaluated in each patient. Flow was measured through a heated pneumotachograph (Fleisch No. 2; Fleisch, Lausanne, Switzerland) that was placed between the Y-shaped piece of the ventilator circuit and the endotracheal tube. The pneumotachograph was linear over the experimental range of flows. $\mathrm{V}_{\mathrm{T}}$ was recorded by numerical integration of the flow signal. The airway opening pressure (Pao) was measured proximally to the endotracheal tube. Pleural pressure (Ppl) was estimated by assessment of esophageal pressure, which was measured using a thin latex balloon-tipped catheter system that was placed orally and then advanced into the distal intrathoracic portion of the esophagus. Static compliance of the respiratory system (Cstat ${ }_{\mathrm{rs}}$ ) was computed at baseline, 5', and 30' as $\operatorname{Cstat}_{\mathrm{rs}}\left(\mathrm{mL} / \mathrm{cm} \mathrm{H}_{2} \mathrm{O}\right)=\mathrm{V}_{\mathrm{T}} /\left(\mathrm{Pao}_{\text {plat }}-\mathrm{PEEP}_{\text {tot }}\right)$, where $\mathrm{Pao}_{\text {plat }}$ corresponds to the value of $\mathrm{Pao}$ at the end of an end-inspiratory pause. The static compliance of the lung (Cstat $)$ was computed at baseline, $5^{\prime}$, and $30^{\prime}$ as Cstatl $\left(\mathrm{mL} / \mathrm{cm} \mathrm{H}_{2} \mathrm{O}\right)=\mathrm{VT} /\left(\mathrm{PaO}_{\text {transp }}\right.$ $\mathrm{PEEP}_{\text {transp }}$ ) where $\mathrm{Pao}_{\text {transp }}$ corresponds to the difference between $\mathrm{PaO}_{\text {plat }}$ and the pleural pressure at the end of an end-inspiratory pause $\left(\mathrm{Ppl}_{\mathrm{plat}}\right)$. The static compliance of the chest 
wall (Cstat $\left.{ }_{\mathrm{cw}}\right)$ was computed at baseline, 5', and 30' as Cstat ${ }_{\mathrm{cw}}\left(\mathrm{mL} / \mathrm{cm} \mathrm{H}_{2} \mathrm{O}\right)=\mathrm{V}_{\mathrm{T}} /\left(\mathrm{Ppl}_{\text {plat }}\right.$ PEEO $\left._{\text {tot,pl }}\right)$ where PEEP $_{\text {tot,pl }}$ corresponds to the PEEP value recorded on the esophageal trace. Arterial blood samples were anaerobically collected at baseline, 5', and 30' before obtaining the computed tomography $(\mathrm{CT})$ images and immediately analyzed. Arterial blood $\mathrm{pH}(\mathrm{pH})$ and blood gas partial pressures of $\mathrm{O}_{2}$ and $\mathrm{CO}_{2}\left(\mathrm{PaO}_{2}\right.$ and $\left.\mathrm{PaCO}_{2} ; \mathrm{mm} \mathrm{Hg}\right)$ were measured. Blood gas and related analyses were performed using an automated, daily calibrated, arterial blood gas (ABG) analyzer. All ABG values were corrected by the analyzer for the body temperature of the animal measured at the time of sampling. Employing the alveolar gas equation, $\mathrm{P}(\mathrm{A}-\mathrm{a}) \mathrm{O}_{2}$ was calculated for each patient as $\mathrm{P}(\mathrm{A}-\mathrm{a}) \mathrm{O}_{2}=$ $\left[\left(\mathrm{P}_{\mathrm{B}}-\mathrm{P}_{\mathrm{H} 2 \mathrm{O}}\right) \times \mathrm{FiO}_{2}-\mathrm{PaCO}_{2}\right]-\mathrm{PaO}_{2}$, where $\mathrm{P}_{\mathrm{B}}$ is the barometric pressure and $\mathrm{P}_{\mathrm{H} 2 \mathrm{O}}$ is the water vapor pressure. $\mathrm{P}_{\mathrm{B}}$ was recorded by the $\mathrm{ABG}$ analyzer during each analysis, and $\mathrm{P}_{\mathrm{H} 2 \mathrm{O}}$ was corrected for the rectal temperature of the patient recorded at the time of arterial blood collection.

To assess lung aeration, a spiral CT of the thorax was performed in all patients at baseline, $5^{\prime}$, and $30^{\prime}$. Each dog was placed upon a positioning device, in dorsal recumbence and restrained symmetrically with anterior legs forward on the CT cot using adhesive strips. A third-generation spiral CT instrument (GE ProSpeed sx ${ }^{\circledR}$, General Electric, USA) was used for the thoracic CT exam. All images were acquired during end-expiratory apnea that was obtained by disconnecting the patient from the ventilator at the time of CT scanning.

All CT images were analyzed for the presence of lung abnormalities, and in case pathologic changes were detected, all data from these dogs were excluded from further analysis. A blinded operator (VD) analyzed the CT images by means of a computer program (DicomWorks, version 1.3.5; 2000.2002, inviweb, Philippe Peuch - Loic BOUSSEL). Both right and left lungs were chosen as regions of interest (ROIs) for analysis. The part of the pulmonary hila containing the trachea, main bronchi, and hilar blood vessels were excluded from the ROI. The computer software plotted the distribution of radiographic attenuations expressed in Hounsfield Units (HUs) among the selected ROIs. The total area $\left(\mathrm{mm}^{2}\right)$ of the right and left lungs was calculated by including pixels with density values between $-1,000$ and +100 HUs. In accordance with previous studies (Staffieri et al. 2007, 2009), four different regions were identified within the lungs: hyperinflated ( $-1,000$ to $-901 \mathrm{HUs})$, normally aerated ( -900 to $-501 \mathrm{HUs})$, poorly aerated ( -500 to $-101 \mathrm{HUs})$, and non-aerated $(-100$ to $+100 \mathrm{HUs}$, indicating complete atelectasis). The area of each compartment was computed and expressed as the percentage of total lung surface. For all recorded numeric variables, the means \pm standard deviations (SDs) at each study time were calculated. Normal distribution of data was verified by means of the Kolmogorov-Smirnow test. Data regarding gas exchange $\left[\mathrm{PaO}_{2}, \mathrm{PaCO}_{2}\right.$, and $\left.\mathrm{P}(\mathrm{A}-\mathrm{a}) \mathrm{O}_{2}\right]$, lung aeration (percentage of hyperinflated, normally aerated, poorly aerated, and atelectasic lung compartments) and respiratory mechanics $\left(\mathrm{Cstat}_{\mathrm{rs}}, \mathrm{Cstat}_{1}\right.$, and $\mathrm{Cstat}_{\mathrm{cw}}$ ) were compared at each study time with a one-way analysis of variance (ANOVA) for repeated measurements, followed by the Student-Newman-Kleus test. A $P$ value less than 0.05 was considered significant.

\section{Results}

The study was conducted without any complications. Data regarding $\mathrm{HR}, \mathrm{RR}, \mathrm{SpO}_{2}, \mathrm{EtCO}_{2}$, and MAP did not show any statistical differences at any study time. At 5', a reduction of the atelectasic lung compartment $\left(5^{\prime}=3.29 \pm 1.25 \%\right.$; baseline $\left.=4.31 \pm 1.41 \%\right)$ and an increase of the normally aerated lung compartment $\left(5^{\prime}=76.94 \pm 7.34 \%\right.$; baseline $\left.=74.85 \pm 8.90 \%\right)$ were 
recorded, while the poorly aerated and hyperinflated lung compartments did not show any significant differences compare to baseline. At 30', the atelectasis lung compartment significantly increased compared to this compartment at $5^{\prime}(4.59 \pm 1.24 \%)$, reaching levels similar to baseline, while the normally aerated lung compartment was significantly reduced compared to this compartment at $5^{\prime}(74.71 \pm 7.15 \%)$. At $5^{\prime}, \mathrm{PaO}_{2}$ increased $\left(5^{\prime}=568.40 \pm\right.$ $69.24 \mathrm{~mm} \mathrm{Hg}$; baseline $=448.30 \pm 100.95 \mathrm{~mm} \mathrm{Hg}$ ) while $\mathrm{P}(\mathrm{A}-\mathrm{a}) \mathrm{O}_{2}$ decreased significantly $\left(5^{\prime}=91.22 \pm 66.68 \mathrm{~mm} \mathrm{Hg}\right.$; baseline $\left.=203.98 \pm 95.23 \mathrm{~mm} \mathrm{Hg}\right)$ compared to baseline. At 30', $\mathrm{PaO}_{2}$ decreased $(475.00 \pm 54.87 \mathrm{~mm} \mathrm{Hg})$ while $\mathrm{P}(\mathrm{A}-\mathrm{a}) \mathrm{O}_{2}$ increased $(120.61 \pm 36.01 \mathrm{~mm} \mathrm{Hg})$ compared to 5', reaching levels similar to baseline. The mean values of Cstat $_{\mathrm{rs}}$, Cstat , and Cstat $_{\mathrm{cw}}$ did not show any significant differences at any study time.

\section{Discussion}

The results of this study demonstrate that in healthy dogs under general anesthesia positioned in dorsal recumbence, an RM is able to temporary improve lung aeration and gas exchange, recruiting the atelectasic lung compartment. The main consequence of atelectasis formation during inhalant anesthesia is the impairment of both pulmonary gas exchange and lung compliance. Formation of completely atelectasic lung units and those with low VA/Q ratios is responsible for the reduction of arterial oxygenation $\left(\mathrm{PaO}_{2}\right)$. In collapsed lung areas that remain perfused, a complete shunt situation develops with a loss of gas exchange. Perfusion of regions with low VA/Q ratios will also impede oxygenation of blood to the extent that is directly related to the change in VA/Q (Duggan and Kavanag 2005). PEEP and RMs are ventilation techniques that are most commonly applied to intra-operative treatment of anesthesia-related atelectasis to achieve a re-expansion of collapsed alveoli. Several clinical and experimental studies in human medicine have already demonstrated that sustained inflation of the lung at $40 \mathrm{~cm} \mathrm{H}_{2} \mathrm{O}$ is able to completely recruit the lung (Johnson 2004). Our results are in agreement with these human studies. The time-dependent effect (20-30 min) of the RM in our study can be attributed to the influence of the high $\mathrm{FiO}_{2}$ that promotes a rapid collapse of the previously recruited alveolar units (de-recruitment) (Dantzker et al. 1975). The results of this study provide important input for clinical practice: a RM can be a valid technique to obtain temporary improvement in lung function during general anesthesia in dogs. The RM can be repeated regularly during anesthesia to prolong its positive effects. We should also consider that due to the potential negative effects of a RM on lung parenchyma and the cardiovascular system, the systematic execution of this technique during an anesthetic episode should be limited in critically ill patients.

\section{References}

Dantzker DR, Wagner PD, West JB (1975) Instability of lung units with low $\mathrm{V}_{\mathrm{A}} / \mathrm{Q}$ ratios during $\mathrm{O}_{2}$ breathing. J Appl Physiol 38:886-895

Duggan M, Kavanag BP (2005) Pulmonary atelectasis: A pathogenic perioperative entity. Anesthesiology 102:838-854

Johnson D (2004) Lung recruitment during general anesthesia. Can J Anesth 51:649-653

Staffieri F, Franchini D, Carella GL et al (2007) Computed tomographic analysis of the effects of two inspired oxygen concentrations on pulmonary aeration in anesthetized and mechanically ventilated dogs. Am J Vet Res 68:925-931

Staffieri F, Bauquier SH, Moate PJ et al (2009) Effects of inspired oxygen concentration on pulmonary gas exchange in anesthetized horses mechanically ventilated with a helium/oxygen gas mixture. Equine Vet $\mathrm{J}$ 41:747-752 